\title{
The Effect of Volunteers' Satisfaction with Volunteer Activities on Sustainability and Life Satisfaction
}

\author{
Nam-Kyo Yun ${ }^{1)}$, Sung-je $\mathrm{Cho}^{2}$
자원봉사자의 자원봉사활동 만족도가 지속성 및 삶의 만족도에 미치는 영향 \\ -서울시 서초구 자원봉사활동 대상자를 중심으로- \\ 윤남교1), 조성제2)
}

\begin{abstract}
The purpose of this study is to understand the effect of volunteers' satisfaction with volunteer activities on sustainability and life satisfaction. The study was conducted on 210 volunteers in Seocho-gu, Seoul. As an analysis method, frequency analysis, reliability analysis, correlation analysis, and regression analysis were performed using the SPSS 19.0 program. As a result of the study, first, it was found that the role value grant and health promotion factors, which are the sub-factors of volunteer satisfaction, have a significant effect on the continuity of volunteer activities. On the other hand, the social contact and social recognition factors of volunteer activity satisfaction were found to have no significant effect on volunteer activity sustainability. Second, the role value grant and social recognition factors, which are sub-factors of volunteer activity satisfaction, were found to have a significant effect on life satisfaction. On the other hand, it was confirmed that social contact and health promotion factors of volunteer activity satisfaction did not significantly affect life satisfaction. This study is considered to be the basic data for the preparation of practical intervention plans to improve volunteers' sustainability and life satisfaction.
\end{abstract}

Keywords: Volunteer, Volunteer Activity Satisfaction, Sustainability, Life Satisfaction

Received(March 23, 2020), Review Result(1st: April 20, 2020, 2nd: June 11, 2020), Accepted(June 25, 2020)

1) (Ph.D. course/doctorate course) 02838 Dept. of Culture and Art, Dongbang Culture Graduate University, 28 Sungbok-Ro, Sungbokdong, Seoul, Korea

email: fy2001@naver.com

2) (Professor, Corresponding Author) 02838 Dept. of Culture and Art, Dongbang Culture Graduate University, 28 Sungbok-Ro, Sungbokdong, Seoul, Korea

email: chosj715@daum.net 


\section{The Effect of Volunteers' Satisfaction with Volunteer Activities on Sustainability and Life Satisfaction}

요 약

본 연구의 목적은 자원봉사자의 자원봉사활동 만족도가 지속성 및 삶의 만족도에 미치는 영향에 대 하여 파악하는 데 있다. 연구대상은 서울특별시 서초구 자원봉사자 210명을 설문대상으로 설문하였다. 분석 방법은 SPSS 19.0 프로그램을 사용하여 신뢰도분석, 빈도 분석을 하였다. 또한, 상관분석과 회귀 분석을 실시하였다. 연구 결과 첫째, 자원봉사자의 자원봉사활동 만족도의 하위요인인, 건강증진 요인 은 자원봉사활동 지속성에 유의한 영향을 미치는 것으로 나타났다. 반면, 자원봉사활동 만족도의 사 회적 접촉, 사회적 인정 요인은 자원봉사활동 지속성에 영향이 없는 것으로 조사되었다. 둘째, 자원봉 사자의 자원봉사활동 만족도의 하위요인인 역할가치부여, 사회적 인정 요인은 삶의 만족도에 유의한 영향을 미치는 것으로 나타났다. 반면, 자원봉사활동 만족도의 사회적 접촉, 건강증진 요인은 삶의 만 족도에 영향이 없는 것으로 조사되었다. 본 연구는 자원봉사자의 자원봉사 활동 지속성 및 삶의 만족 도 향상을 위한 정책 자료가 될 것으로 판단된다.

핵심어: 자원봉사자, 자원봉사 활동 만족도, 지속성, 삶의 만족도

\section{1. 서론}

\section{1 연구의 필요성}

최근 고령화 사회에 접어들면서 노인부양이 사회적 문제로 확대되고 있는 추세이다. 또한, 고령의 노인들은 중증질환으로 타인에 의해 케어를 받아야 한다. 반면 핵가족 사회 및 여성의 경제활동 증가로 중증질환 노인들을 가정에서 부양하기가 어려운 것이 현실적인 문제이다. 이러한 노인문제 를 해결하기 위해 국가에서 사회복지정책을 시행하고 있으나, 정부의 복지정책에 의해 노인 및 취 약 계층의 삶의 질에 대한 문제를 근본적으로 해결할 수는 없다. 이러한 노인 문제에 대해 해결 방안의 일환으로 자원봉사단체가 자원봉사활동을 수행하고 있다. 따라서 자원봉사의 활성화 측면 에서 자원봉사자의 봉사활동 만족도와 지속성이 강조되고 있다.

자원봉사 관련 기관에서는 민간차원에서 자원봉사 활성화를 위한 실천적 노력이 이루어지고 있 고, 정부와 지방자치단체에서는 자원봉사의 관리적 측면에서 자원봉사활동을 위한 지원이 되고 있 다. 반면 1365(자원봉사 포털, 행정자치부)에 따르면, 자원봉사자의 수가 2018년도 30,619,226명에서 2019년도 29,129,700명으로 매년 줄어드는 것으로 보고되었다[1]. 이는 자원봉사자의 참여 동기도 중요하지만, 지속성이 무엇보다 자원봉사의 활성화 측면에서는 매우 중요하다. 따라서 자원봉사의 활성화를 위해 관리적 차원에서 자원봉사 만족도가 매우 중요한 부분이지만[2] 자원봉사자의 지속 성에 미치는 영향에 대해 구체적인 분석은 시의적으로 의미가 크다. 특히 자원봉사활동 만족도와 지속성의 영향요인 관계를 살펴보는 것은 매우 중요하다.

자원봉사활동의 지속성이란 “자원봉사자들의 참여 동기로부터 발현된 봉사활동이 가져다주는 보상에 대한 사회적 산물"[3]이며, 자원봉사자의 지속성은 봉사활동이 관리적 차원에서 매우 중요 한 변인이다. 또한, 자원봉사활동은 자원봉사자가 타인에게 도움을 주면서, 자신의 자원봉사활동 만족도가 중요하다. 그 이유는 자원봉사활동 만족도가 지속성에 영향요인으로 작용하기 때문이다. 이에 이론적 근거를 살펴보면, 자원봉사활동 만족도가 높으면 자원봉사활동의 지속성이 높다는 연 
구결과가 보고되었다[2]. 이러한 결과를 볼 때, 자원봉사활동 만족도는 자원봉사에 대한 지속의지 에 중요한 요인이므로 체계적인 연구가 필요하다. 이를 실증적으로 검증한 많은 연구는 자원봉사 자의 만족도가 높을수록 자원봉사 지속성에 긍정적인 영향을 미치고 있으며[4][5], 자원봉사활동 지 속성이라는 효과의 선행조건이 자원봉사만족도라는 것을 주장하고 있다. 이 의미는 자원사자들의 봉사활동만족은 봉사활동을 지속시킬 수 있는 요인으로 작용하여 봉사활동의 활성화 측면에서 중 중요함이 확인되었다. 그러므로 자원봉사자들이 만족할 수 있는 다양한 프로그램과 지속의지 관리 체계를 마련되어야 할 것이다. 이에 자원봉사자의 봉사활동만족도와 지속성에 영향을 미치는 요인 에 대한 연구가 필요한 것으로 판단된다.

한편, 자원봉사자들에게 필요한 것은 물질적인 이기심보다는 자원봉사를 통하여 심리적인 보람 이나 삶의 만족 등을 더 많이 느낄 수 있도록 해야 할 것이며, 이를 위한 여러 가지 실천적인 방 안들이 마련되어야 할 것이다. 왜냐하면, 봉사활동만족도는 삶의 의미에 긍정적인 영향을 미치고 있으며[6], 자원봉사자의 삶의 질 정도는 자원봉사만족이라고 설명되고 있다[7]. 따라서 자원봉사자 의 봉사활동만족도는 자원봉사활동의 지속성과 삶의 질에 영향을 미치는 것으로 가정할 수 있다. 이에 자원봉사자의 봉사활동만족도는 삶의 만족도에 미치는 영향을 살펴볼 필요가 있다.

이상의 논의를 종합할 때, 자원봉사자의 자원봉사활동 지속성과 삶의 만족도에 영향을 미치는 봉사활동만족도 요인에 대한 연구가 필요하다. 또한, 자원봉사자의 지속성과 삶의 만족도 대한 영 향을 미치는 요인을 파악하여 자원봉사의 활성화 방안을 제시하고자 한다.

\section{2 연구문제}

본 연구의 목적은 자원봉사자의 자원봉사 활동 만족도가 자원봉사활동 지속성 및 삶의 만족도에 미치는 영향에 대하여 분석하는 데 있다. 구체적인 연구문제는 아래와 같다.

첫째, 자원봉사자의 자원봉사 활동 만족도와 자원봉사활동 지속성과의 관계는 어떠한가?

둘째, 자원봉사자의 자원봉사 활동 만족도가 삶의 만족도에 영향을 미치는가?

\section{2. 연구방법}

\section{1 연구대상}

본 연구는 자원봉사자의 자원봉사 활동 만족도가 자원봉사 활동 지속성에 미치는 영향과 그 영향 과의 관계에서 삶의 만족도에 어떠한 영향을 미치는가를 살펴보고자 하였다. 이를 위하여 2019년 3월 1일부터 2019년 5월 31일까지 서울특별시 서초구에 거주하며 자원봉사에 참여한 경험이 있는 240명을 대상으로 설문지를 배부하였으며, 설문대상자에게 설문내용을 상세히 설명한 후 설문을 수행하였다. 총 225 부를 수집하여 $93.7 \%$ 의 회수율을 보였으며, 회수된 설문지 중 불성실하게 답변 


\section{The Effect of Volunteers' Satisfaction with Volunteer Activities on Sustainability and Life Satisfaction}

하거나, 중복 또는 누락된 경우 등 분석에 적합하지 않은 설문지 15 부를 제외한 210 부로 본 연구 의 자료로 적용하였다.

\section{2 연구도구}

본 연구에 사용된 도구는 일반적 특성 4 문항, 자원봉사 활동 만족도 16 문항, 지속성 6 문항, 삶의 만족도 15 문항으로 구성되어 있다. 일반적 특성에 관한 내용은 성별, 연령, 학력, 월 소득수준 등으 로 구성하여 조사하였다. 자원봉사자의 자원봉사 활동 만족도를 측정하기 위해 강희진[8]이 사용한 자원봉사 활동 만족도의 측정도구는 하위요인 역할가치부여 4 문항, 사회적 접촉 4 문항, 사회적 인 정 4 문항, 건강증진 4 문항 총 16 문항으로 구성하였다. 설문지 문항은 리커트 5점 척도로 구성하였 다. 자원봉사자의 자원봉사 활동 지속성을 측정하기 위해 박춘희[3]의 지속성 측정도구는 앞으로 자원봉사 활동에 대한 지속의지와 참여강도에 대한 내용으로 6 문항을 사용하여 리커트 5점 척도로 구성하였다. 그리고 자원봉사자의 삶의 만족도를 측정하기 위해 장혜진[9]의 삶의 만족도 연구에 사용한 도구를 사용하였다. 측정도구의 15 문항을 사용하였으며, 설문지 문항은 리커트 5 점 척도 로 구성하였다.

\section{3 신뢰도}

본 연구에 사용된 각 변수의 신뢰도 검증 결과 자원봉사활동 만족도 .958 , 자원봉사활동 지속성 .859 , 삶의 만족도 .961로 높은 신뢰도를 보이고 있다. 신뢰도는 Cronbach's a값으로 하였으며, 본 연구의 결과는 모두 .60이상으로 나타났다. 신뢰도 분석 결과에 대한 구체적인 내용은 [표 1]과 같 이 나타났다.

[표 1] 주요 변수의 신뢰도

[Table 1] Reliability of Key Variables

\begin{tabular}{ccc}
\hline 구분 & 문항수 & Cronbach's $\alpha$ \\
\hline 자원봉사활동 만족도 & 16 & .958 \\
자원봉사활동 지속성 & 6 & .859 \\
삶의 만족도 & 15 & .961 \\
\hline
\end{tabular}

\section{4 자료처리 및 분석방법}

연구에 수집된 자료처리는 SPSS 19.0 프로그램을 사용하여 유의수준 $5 \%$ 에서 검증하였고, 각 연구 도구의 신뢰도 산출은 Cronbach's a의 계수를 이용하여 분석하였다. 자원봉사자의 일반적 특성은 빈도분석을 실시하여 알아보았으며, 주요 변수에 대한 상관분석을 실시하였다. 그리고 자원봉사자 

의 자원봉사 활동 만족도 지속성, 삶의 만족도의 인과과계를 알아보기 위하여 다중회귀분석을 실 시하였다.

\section{3. 연구결과}

\section{1 인구 사회학적 특성}

본 연구대상자의 인구사회학적 특성을 살펴보면, 자원봉사자의 성별은 남자 88 명 $(41.9 \%)$, 여자 122 명 $(58.1 \%)$ 으로 여자의 비율이 더 높은 것으로 나타났다. 연령은 50대가 67 명 $(31.9 \%)$ 으로 가장 많았 고, 40 대 48 명(22.9\%), 60대 이상 39명(18.6\%), 20대 이하 35명(16.7\%), 30대 21 명 $(10.0 \%)$ 순으로 나 타났다. 학력은 전문대 및 대졸이 108 명(51.4\%)으로 가장 많은 것으로 나타났으며, 고졸 이하가 53 명(25.2\%), 대학원 졸업 이상이 49 명 $(23.3 \%)$ 순으로 파악되었다. 월 소득수준은 450 만원 이상이 77 명 $36.7 \%)$ 으로 가장 많은 것으로 파악되었으며, 250 만원 이상 350 만원 미만 50 명 $(23.8 \%), 150$ 만원 이상 250 만원 미만 38 명(18.1\%), 350만원 이상 450 만원 미만 31명(14.8\%), 150 만원 미만 14 명 $(6.7 \%)$ 순으로 나타났다. 자원봉사자의 인구사회학적 특성에 대하여 살펴본 결과는 [표 2]와 같다.

\section{[표 2] 인구사회학적 특성}

[Table 2] Sociodemographic Characteristics

\begin{tabular}{|c|c|c|c|}
\hline \multirow{2}{*}{\multicolumn{2}{|c|}{ 구분 }} & \multicolumn{2}{|c|}{ 전체 $(\mathrm{N}=210)$} \\
\hline & & \multirow{2}{*}{$\begin{array}{c}\text { 빈도(명) } \\
88\end{array}$} & 비율(\%) \\
\hline \multirow{2}{*}{ 성별 } & 남자 & & 41.9 \\
\hline & 여자 & 122 & 58.1 \\
\hline \multirow{5}{*}{ 연령 } & 20대 이하 & 35 & 16.7 \\
\hline & 30대 & 21 & 10.0 \\
\hline & 40대 & 48 & 22.9 \\
\hline & 50대 & 67 & 31.9 \\
\hline & 60대 이상 & 39 & 18.6 \\
\hline \multirow{3}{*}{ 학력 } & 고졸 이하 & 53 & 25.2 \\
\hline & 전문대 및 대졸 & 108 & 51.4 \\
\hline & 대학원졸 이상 & 49 & 23.3 \\
\hline \multirow{5}{*}{ 월 소득수준 } & 150만원 미만 & 14 & 6.7 \\
\hline & 150 만원 이상-250만원 미만 & 38 & 18.1 \\
\hline & 250만원 이상-350만원 미만 & 50 & 23.8 \\
\hline & 350 만원 이상-450만원 미만 & 31 & 14.8 \\
\hline & 450만원 이상 & 77 & 36.7 \\
\hline
\end{tabular}




\section{2 주요 변수에 대한 기술통계}

자원봉사자의 주요 변수에 대한 측정 변수는 5점 척도로 측정하였다. 자원봉사활동 만족도의 하위 요인별로 살펴보면, 사회적 접촉( $\mathrm{M}=3.73)$ 요인이 가장 높게 나타났고, 사회적 인정 $(\mathrm{M}=3.62)$, 역할 가치부여 $(\mathrm{M}=3.57)$, 건강증진 $(\mathrm{M}=3.11)$ 순으로 나타났다. 전체 자원봉사 활동 만족도( $\mathrm{M}=3.51)$ 요인은 평균 점수 이상의 수준으로 나타난 것을 알 수 있다. 자원봉사활동 지속성 $(\mathrm{M}=3.43)$ 요인과 삶의 만족도( $\mathrm{M}=3.62)$ 요인 또한, 평균 점수 이상의 수준인 것으로 나타났다. 자원봉사자의 주요 변수에 대한 기술통계를 살펴본 결과는 [표 3]과 같다.

[표 3] 주요 변수에 대한 기술통계

[Table 3] Reliability of Key Variables

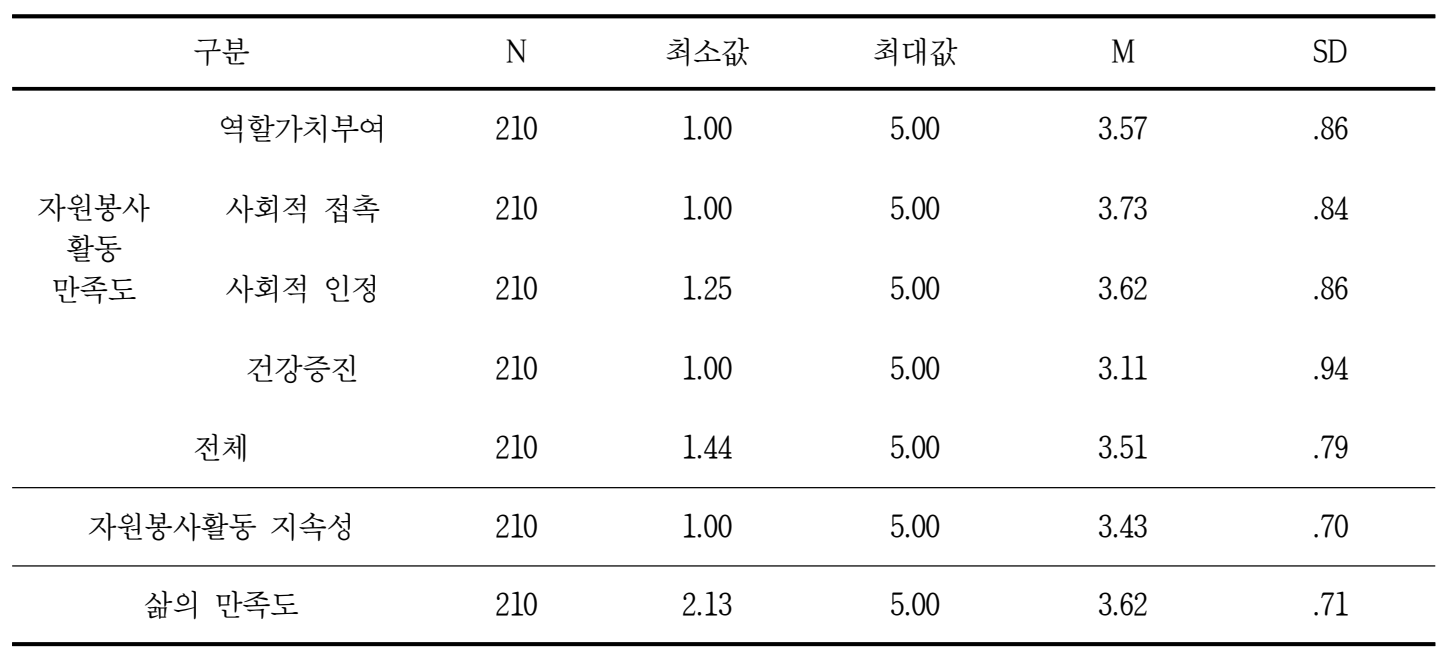

\section{3 변수 간의 상관관계}

자원봉사자의 자원봉사활동 만족도의 하위요인인 역할가치부여, 사회적 접촉, 사회적 인정, 건강증 진과 지속성 및 삶의 만족도의 관련성을 살펴보았다. 분석결과 자원봉사자가 인식하는 역할가치부 여 요인과 지속성 요인은 양 $(+)$ 의 상관결과가 나타났다 $(\mathrm{r}=.629, \mathrm{p}<.01)$. 또한, 역할가치부여 요인과 삶의 만족도 요인도 양 $(+)$ 의 상관결과가 나타났다 $(\mathrm{r}=.477, \mathrm{p}<.01)$. 그리고 사회적 접촉 요인과 지속 성 요인은 양 $(+)$ 의 상관결과가 있는 것으로 확인되었다 $(\mathrm{r}=.512, \mathrm{p}<.01)$. 한편 사회적 인정 요인과 지 속성 요인은 양 $(+)$ 의 상관결과로 확인되었다 $(\mathrm{r}=.536, \mathrm{p}<.01)$. 사회적 인정 요인과 삶의 만족도 요인 또한, 양 $(+)$ 의 상관결과로 확인되었다 $(\mathrm{r}=.477, \mathrm{p}<.01)$. 건강증진 요인과 지속성 요인도 양 $(+)$ 의 상관 결과를 지니는 것으로 확인되었다 $(\mathrm{r}=.593, \mathrm{p}<.01)$. 그리고 지속성 요인과 삶의 만족도 요인도 양 $(+)$ 의 상관결과가 있는 것으로 확인되었다 $(\mathrm{r}=.405, \mathrm{p}<.01)$. 반면, 자원봉사자의 사회적 접촉 요인과 삶 
의 만족도 요인은 낮은 양 $(+)$ 의 상관관계로 나타났다 $(\mathrm{r}=.326, \mathrm{p}<.01)$. 건강증진 요인과 삶의 만족도 요인 또한, 낮은 양 $(+)$ 의 상관관계로 나타났다 $(\mathrm{r}=.394, \mathrm{p}<.01)$. 이러한 결과는 각 상관계수 값이 통 계적 유의 수준 하에서 변수 간의 관계성이 있음을 보여주고 있다. 이에 대한 변수 간의 상관분석 결과는 [표 4]와 같이 나타났다.

[표 4] 주요 변수 간의 상관관계

[Table 4] Correlation between Key Variables

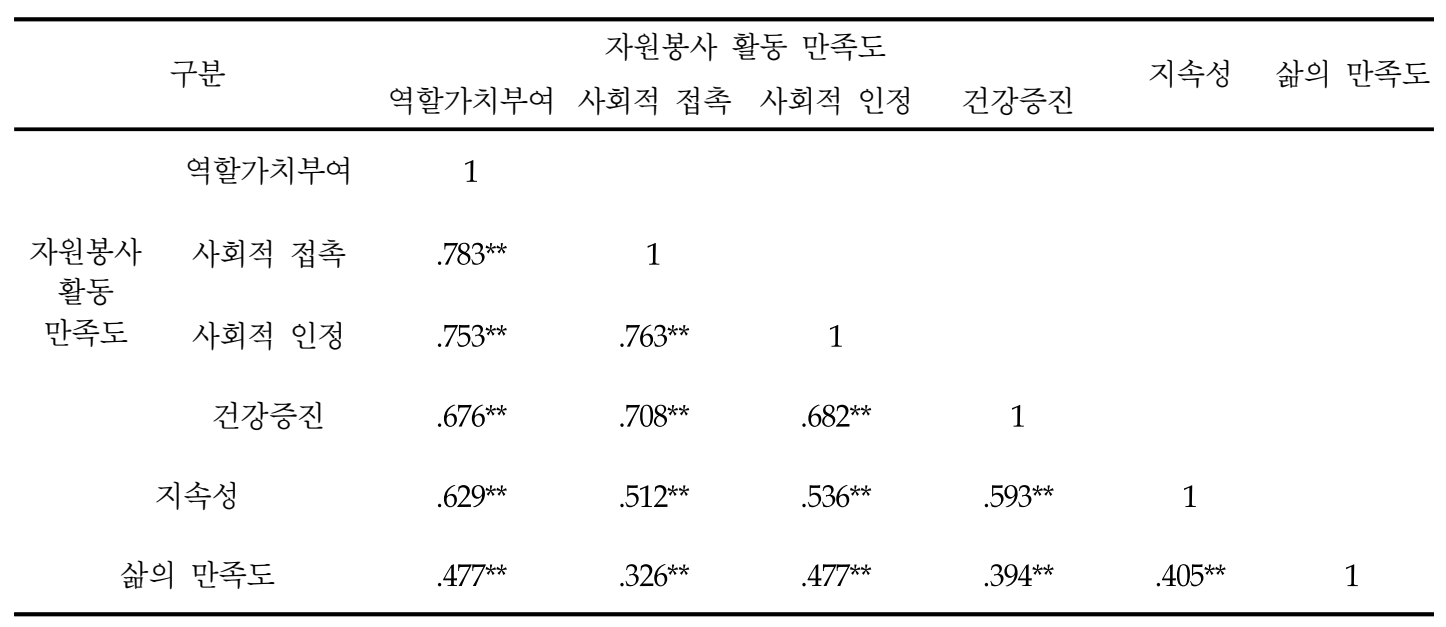

${ }^{*} \mathrm{p}<.05,{ }^{* *} \mathrm{p}<.01$

\section{4 자원봉사자의 자원봉사활동 만족도가 지속성 및 삶의 만족도에 미치는 영향}

\subsection{1 자원봉사자의 자원봉사활동 만족도가 지속성에 미치는 영향}

자원봉사자의 자원봉사활동 만족도가 지속성에 미치는 영향을 알아보기 위하여 다중회귀분석을 실 시하였다. 분석결과, 자원봉사활동 지속성에 대한 자원봉사활동 만족도의 설명력을 의미하는 $\mathrm{R}^{2}$ 값 이 .452 로 나타나 전체 변동의 $45.2 \%$ 로 회귀모형을 설명하고 있다. 자원봉사활동 만족도의 하위요 인별로 영향력을 살펴보면, 역할가치부여 $(\beta=.458, \mathrm{p}<.001)$, 건강증진( $\beta=.332, \mathrm{p}<.001)$ 요인은 자원봉 사활동 지속성에 영향이 미치는 것으로 나타났다. 반면, 자원봉사활동 만족도의 하위요인인 사회적 접촉( $\beta=-.130, \mathrm{p}>.05)$, 사회적 인정( $\beta=.063, \mathrm{p}>.05)$ 요인은 자원봉사활동 지속성에 영향을 미치지 않 는 것으로 나타났다. 이는 자원봉사자의 자원봉사활동 만족도 하위요인 중 역할가치부여와 건강증 진 요인이 높을수록 자원봉사활동 지속성이 높아진다는 것을 의미하는 것이다. 자원봉사자의 자원 봉사활동 만족도가 지속성에 미치는 영향을 살펴본 결과는 [표 5]과 같이 나타났다.

\section{4 .2 자원봉사자의 자원봉사활동 만족도가 삶의 만족도에 미치는 영향}

자원봉사자의 자원봉사활동 만족도가 삶의 만족도에 미치는 영향을 알아보기 위하여 다중회귀분석 


\section{The Effect of Volunteers' Satisfaction with Volunteer Activities on Sustainability and Life Satisfaction}

을 실시하였다. 분석결과, 자원봉사활동 삶의 만족도에 대한 자원봉사활동 만족도의 설명력을 의미 하는 $\mathrm{R}^{2}$ 값이 .295 로 나타나 전체 변동의 $29.5 \%$ 로 회귀모형을 설명하고 있다. 자원봉사활동 만족도 의 하위요인별로 영향력을 살펴보면, 역할가치부여 $(\beta=.389, p<.001)$, 사회적 인정 $(\beta=.356, p<.001)$ 요인은 삶의 만족도에 영향이 미치는 것으로 나타났다. 반면, 자원봉사활동 만족도의 하위요인인 사회적 접촉( $\beta=-.345, \mathrm{p}>.05)$, 건강증진 $(\beta=.132, \mathrm{p}>.05)$ 요인은 삶의 만족도에 영향을 미치지 않는 것으로 나타났다. 이는 자원봉사자의 자원봉사활동 만족도 하위요인 중 역할가치부여와 사회적 인 정 요인이 높을수록 삶의 만족도가 높아진다는 것을 의미하는 것이다. 자원봉사자의 자원봉사활동 만족도가 삶의 만족도에 미치는 영향을 살펴본 결과는 [표 6]과 같이 나타났다.

[표 5] 자원봉사자의 자원봉사활동 만족도가 지속성에 미치는 영향

[Table 5] The Effect of Satisfaction with Volunteer's Sustainability

\begin{tabular}{|c|c|c|c|c|c|c|}
\hline \multirow{2}{*}{ 종속변수 } & \multirow{2}{*}{ 독립변수 } & \multicolumn{2}{|c|}{ 비표준화 계수 } & \multirow{2}{*}{$\begin{array}{c}\text { 표준화 계수 } \\
\beta\end{array}$} & \multirow{2}{*}{$t / p$} & \multirow{2}{*}{$\begin{array}{l}\text { 공차 } \\
\text { 한계 }\end{array}$} \\
\hline & & $B$ & 표준오차 & & & \\
\hline \multirow{5}{*}{ 지속성 } & 상수 & 1.551 & .170 & & $9.128^{* * *}$ & \\
\hline & 역할가치부여 & .374 & .072 & .458 & $5.178^{* * *}$ & .318 \\
\hline & 사회적 접촉 & -.110 & .078 & -.130 & -1.410 & .292 \\
\hline & 사회적 인정 & .052 & .072 & .063 & .732 & .337 \\
\hline & 건강증진 & .249 & .057 & .332 & $4.403^{* * *}$ & .437 \\
\hline \multicolumn{7}{|c|}{$\mathrm{R}^{2}=.452$, 수정된 $\mathrm{R}^{2}=.442$} \\
\hline \multicolumn{7}{|c|}{$\mathrm{F}=45.421, \mathrm{P}=.000$, Durbin-Watson $=1.902$} \\
\hline
\end{tabular}

${ }^{*} \mathrm{p}<.05,{ }^{* *} \mathrm{p}<.01,{ }^{* * *} \mathrm{p}<.001$

[표 6] 자원봉사자의 자원봉사활동 만족도가 삶의 만족도에 미치는 영향

[Table 6] The Effect of Volunteer Activity Satisfaction on Life Satisfaction

\begin{tabular}{|c|c|c|c|c|c|c|}
\hline \multirow{2}{*}{ 종속변수 } & \multirow{2}{*}{ 독립변수 } & \multicolumn{2}{|c|}{ 비표준화 계수 } & 표준화 계수 & \multirow{2}{*}{$\mathrm{t} / \mathrm{p}$} & \multirow{2}{*}{$\begin{array}{l}\text { 공차 } \\
\text { 한계 }\end{array}$} \\
\hline & & $B$ & 표준오차 & $\beta$ & & \\
\hline \multirow{5}{*}{$\begin{array}{c}\text { 삶의 } \\
\text { 만족도 }\end{array}$} & 상수 & 2.206 & .190 & & $11.605^{* * *}$ & \\
\hline & 역할가치부여 & .314 & .081 & .389 & $3.878^{* * *}$ & .318 \\
\hline & 사회적 접촉 & -.288 & .087 & -.345 & -3.291 & .292 \\
\hline & 사회적 인정 & .293 & .080 & .356 & $3.650^{* * *}$ & .337 \\
\hline & 건강증진 & .098 & .063 & .132 & 1.545 & .437 \\
\hline \multicolumn{7}{|c|}{$\mathrm{R}^{2}=.295$, 수정된 $\mathrm{R}^{2}=.283$} \\
\hline \multicolumn{7}{|c|}{$\mathrm{F}=23.058, \mathrm{P}=.000$, Durbin-Watson $=2.106$} \\
\hline
\end{tabular}

${ }^{*} \mathrm{p}<.05,{ }^{* *} \mathrm{p}<.01,{ }^{* * *} \mathrm{p}<.001$ 


\section{4. 결론 및 제언}

본 연구에서는 자원봉사자의 자원봉사 활동 만족도의 차이에 대하여 분석하였다. 분석결과를 토대 로 구체적으로 논의하면 다음과 같다.

첫째, 자원봉사자의 자원봉사활동 만족도의 하위요인인 역할가치부여, 건강증진 요인은 자원봉 사활동 지속성에 유의한 영향을 미치는 것으로 나타났다. 반면, 자원봉사활동 만족도의 하위요인인 사회적 접촉, 사회적 인정 요인은 자원봉사활동 지속성에 유의한 영향을 미치지 않는 것으로 확인 되었다. 이는 자원봉사자의 자원봉사활동 만족도 하위요인 중 역할가치부여, 건강증진 요인이 높을 수록 자원봉사활동 지속성이 높아진다는 것을 의미하는 것이다. 이러한 결과는 의용소방대 대원 인 경우는 만족도의 하위요인 중에서 '사회접촉' '경험 욕구', '사회인정'이 지속성에 유의한 영향 을 미쳤다는 연구결과[10]과 반대의 결과로 나타났다. 이 의미는 의용소방대 대원의 만족도는 국민 의 생명안전을 중요시하는 업무이므로 사회접촉이나 사회인정이 영향을 미치는 것으로 판단된다. 반면 일반인을 대상으로 하는 자원봉사자인 경우는 역할가치부여와 건강증진 요인이 자원봉사활동 지속성에 중요한 변인임을 알 수 있다. 결과적으로 자원봉사활동 만족도 하위요인 중에서 역할가 치부여와 건강증진요인이 자원봉사활동 지속성이 향상된다는 것이 확인되었다.

둘째, 자원봉사자의 자원봉사활동 만족도의 하위요인인 역할가치부여, 사회적 인정 요인은 삶의 만족도에 유의한 영향을 미치는 것으로 나타났다. 반면, 자원봉사활동 만족도의 하위요인인 사회적 접촉, 건강증진요인은 삶의 만족도에 유의한 영향을 미치지 않는 것으로 확인되었다. 이는 자원봉 사자의 자원봉사활동 만족도 하위요인 중 역할가치부여와 사회적 인정 요인이 높을수록 삶의 만족 도가 높아진다는 것을 의미하는 것이다. 이러한 결과는 자원봉사활동을 통하여 노인들도 사회적 기여감이나 성취감과 같은 만족도가 클수록 삶의 만족도 향상에 유의미한 상관이 있다는 연구결과 [11]과 일치하였다. 이 의미는 자원봉사자의 대상이 누구나 상관없이 역할가치부여나 사회적 인정 요인은 삶의 만족도에 유의한 영향을 미치는 것으로 판단된다. 결과적으로 자원봉사활동 만족도 하위요인 중에서 역할가치부여와 사회적 인정요인이 삶의 만족도 향상에 중요한 변인으로 확인되 었다.

이상의 논의된 바와 같이 자원봉사활동의 활성화 측면에서 자원봉사활동의 지속성이 매우 중요 하다. 본 연구에서는 자원봉사활동 만족도가 지속성 및 삶의 만족도에 미치는 영향을 분석하였다 는 데 의의가 있다고 본다. 향후 자원봉사활동의 지속성을 향상시킬 수 있는 연구가 필요하다. 향 후 자원봉사자를 대상으로 지속성 향상에 대해 심층적인 연구가 요구된다. 


\section{References}

[1] https://www.1365.go.kr/vols/main.do, May 27 (2019)

[2] Mi Ae Yang, A Study on Satisfaction with Continuity of Volunteerism, The Journal of Humanities and Social Science, (2016), Vol.7, No.2, pp.275-297.

[3] C. H. Park, A Study of the Factors Affecting Citizens' Sustainable Participation in Voluntary Activities, Konkuk University, Doctoral Dissertation, (2015)

[4] Tae-Kon Kim, Hwang-Gun Ryu, Sung-Kwon Bae, A Study on Influential Factors for the Continuance of Hospital Volunteer Activities, Korea Society of Health Service Management, (2011), Vol.5, No.3, pp.191-202.

[5] C. L. Kim, A Study on the Factors Affecting the Sustainability of Volunteer Activities, Social Science Research Review, (2016), Vol.32, No.2, pp.83-115.

[6] G. J. Park, Satisfaction for Voluntary Activity and the Meaning of Life in Hospice Volunteers, Asian Oncology Nursing, (2006), Vol.6, No.2, pp.104-110.

[7] G. E. Han, U. S. Choe, Quality of Life and Related Factors in Hospice Volunteers, Asian Oncology Nursing, (2006), Vol.6, No.2, pp.143-151.

[8] H. J. Kang, The influence of volunteer's emotional quotient on volunteer's voluntary work satisfaction level and psychological wellbeing: Focusing on self-efficacy mediator effect, Dongbang Culture University, Doctoral Dissertation, (2016)

[9] H. J. Jang, The Impact of Middle Age Women`s Social Volunteering on Psychological Wellbeing -Mediated Effect of Life Satisfaction and Depression-, Seoul Hanyoung University, Doctoral Dissertation, (2016)

[10] Seyoung Lim, Hyeonji Lee, Miyoung Choi, Jeonghyeon Hwang, Munui Kim, Taeyoung Moon, Impact of Disaster Perception and Satisfaction on the Continuity of Volunteering in Volunteer Fire-fighters, Journal of The Korean Society of Disaster Information, (2015), Vol.11, No.2, pp.191-202.

[11] Ga Eon Lee, Rejae Ha Kim, Relationship between Satisfaction of Volunteering and Meaning in Life of the Elderly -based on hospital Voluntary Activity, Journal of Korean Academy of Community Health Nursing, (2006), Vol.17, No.3, pp.326-334. 